\title{
In vitro Screening and Chemometrics Analysis on a Series of Azole Derivatives with Fungicide Activity Against Moniliophthora perniciosa
}

\author{
Sabrina G. R. Mota, ${ }^{a}$ Tânia F. Barros ${ }^{b}$ and Marcelo S. Castilho ${ }^{*, b}$ \\ ${ }^{a}$ Programa de Pós-Graduação em Biotecnologia,Universidade Estadual de Feira de Santana, \\ 44036-900 Feira de Santana-BA, Brazil
}

${ }^{b}$ Faculdade de Farmácia,Universidade Federal da Bahia, 40170-115 Salvador-BA, Brazil

\begin{abstract}
Moniliophthora perniciosa, o agente causal da vassoura-de-bruxa do cacaueiro, diminuiu significativamente a produção de cacau, especialmente no estado da Bahia, a maior região produtora de cacau do continente americano. As formas de controle desenvolvidas até o momento têm baixa eficiência. Derivados de azol são ativos tanto in vitro quanto in loco contra M. perniciosa, porém não há um estudo sistemático sobre a atividade dos azóis contra este fitopatogeno. Dados biológicos, obtidos em um ensaio padronizado, foram utilizados para criação de modelos quimiométricos, que destacam características físico e estruturais importantes para a atividade fungicida de derivados de azol frente a $M$. perniciosa. De acordo com os modelos de PCA e SIMCA, características eletrônicas, representadas pelos descritores BEHe3 e JGI4, paralelamente à possibilidadde de realizar ligações de $\mathrm{H}$ e ausência de átomos de cloro, distantes de 6-8 ligações dos nitrogênios do anel azólico, parecem contribuir para atividade fungicida dos compostos estudados
\end{abstract}

Moniliophthora perniciosa, the causal agent of witches' broom disease in Theobroma cacao, significantly decreased cacao production, especially in Bahia State, the largest cocoa producing of the American continent. Control programs developed so far have low efficiency. Azole derivatives are active both in vitro and in loco against $M$. perniciosa, however there is no comprehensive study on the activity of azoles against this phytopatogen. Standardized in vitro biological data were employed to develop supervised and unsupervised chemometric models that highlight physicochemical and structural features that are crucial for azole's fungicidal activity against $M$. perniciosa. Thus, PCA and SIMCA models suggest that electronegativity (BEHe3) and dipolar moment (JGI4), as well as H-bonding to M. pernciosa's lanosterol $14 \alpha$-desmethylase active site and lack of $\mathrm{Cl}$ atoms 6 to 8 bonds from the azole's nitrogen atoms play a major role to azoles' fungicide activity.

Keywords: witches' broom disease, azole derivates, chemometric analysis, Moniliophthora perniciosa

\section{Introduction}

The basidiomycete Moniliophthora perniciosa (Aime and Phillips-Mora 2005) (Agaricales, Marasmiaceae) is a hemibiotrophic fungus which biotrophic phase causes witches ' broom disease (WBD) in Theobroma cacao. ${ }^{1}$ In Brazil, WBD was detected in the cacao-producing region of Southeastern Bahia in the late 1980s. ${ }^{2}$ Since then, the production of this commodity has severely dropped resulting in the shift of Brazil from the second largest cacao exporter to a cacao importer. ${ }^{3}$ To make matters worse, this disease has caused social and environmental

*e-mail: castilho@ufba.br damage to the region as the local producers are devastating the local tropical forest to sow alternative crops. In order to minimize WBD impact, several control programs have been developed. ${ }^{2,4,5}$ However, all the approaches adopted so far can only partially control the disease. ${ }^{6}$

Indeed, there is a major concern that resistant T. cacao cultivars become susceptible to novel $M$. perniciosa strains. This fear is rooted in the fact that genomic studies identified only two strains of the fungi in Southeastern Bahia region, whereas at least six different strains have been identified in the Amazon region. ${ }^{7}$ As a result, the resistant T. cacao cultivars, selected towards Bahia's strains, may be susceptible to new Amazon's strains. Moreover, Theobroma cacao Scavina 6 genotype, the only source of 
resistant clones currently available, has been found to be susceptible to selected M. perniciosa strains in Ecuador, Amazon and South Bahia. ${ }^{8}$

This scenario underscores the importance of the chemical agents in the control of WBD. Nevertheless, the use of topical fungicides has little or no efficacy against $M$. perniciosa, a fact related to the active growth of infected tissues and the long rainy season in the producing regions. Thus, systemic antifungal are the best chemical alternative to fight WBD. Despite the fact that most compounds evaluated against $M$. perniciosa are active in vitro only, some azole fungicides, such as tebuconazol, hexaconazole and triadmenol are active against $M$. perniciosa both in vitro and in loco. ${ }^{6,9}$ For this reason, the ergosterol pathway inhibitors have been considered as a viable alternative for the controlling WBD. ${ }^{9}$

In order to further investigate $M$. pernicios a susceptibility to azole derivatives and pinpoint the best fungicide to fight WBD, screening of a diverse set of azole was carried out using a novel biological assay that relies on a quasi singlecell suspension of $M$. perniciosa hyphae, first described by Filho and co-workers (2006). ${ }^{10}$ The in vitro results reported herein indicate that not all azole fungicides shall be used to fight WBD as some of them are not effective against $M$. perniciosa. Additionally, the biological profile of azole derivatives was employed to derive supervised and unsupervised 2D chemometric models that highlight physicochemical and structural features that determine azole derivatives fungicidal activity against $M$. perniciosa.

\section{Experimental}

\section{Reagents}

The imidazole and triazole derivates were purchased from the Sigma-Aldrich Fisher Company with purity equal or higher than $95 \%$. All other reagents used in the preparation of culture medium, buffers and so on were acquired from well-known chemical companies and used without further purification.

\section{Fungicidal activity assays}

The fungicide activity of azole derivates against Moniliophthora perniciosa was determined using a susceptibility assay developed upon quasi-single cell suspension of $M$. perniciosa hyphae, as described by Filho and co-workers (2006). ${ }^{10}$ The original protocol was modified as follows: The M. perniciosa $948 \mathrm{~F}$ strain, obtained from CEPLAC (Comissão Executiva do Plano da Lavora Cacaueira - http://www.ceplac.gov.br/index. asp), was inoculated in Petri dishes containing potato dextrose agar (PDA), which were incubated at $28{ }^{\circ} \mathrm{C}$ for 10 days in biological stove with oxygen demand (BDO). After hatching and growth, 2-3 mm diameter blocks were removed from the mycelium periphery and transferred to flasks containing $2 \mathrm{~g}$ of glass beads, acid washed (212-300 mm, G1277 sigma) and $5 \mathrm{~mL}$ of citrate peptone dextrose broth (CPD) supplemented with $2 \%$ dextrose and peptone, and then submitted to intense agitation in Mixtron Vortex, speed 4 for $3 \mathrm{~min}$. Next, a $3 \mathrm{~mL}$ sample of this suspension was inoculated into Erlenmeyer flasks containing $10 \mathrm{~mL}$ of CPD broth, supplemented with $2 \%$ dextrose and peptone and incubated under shaking using a Nova Ética Shaker, Model 109, at $200 \mathrm{rpm}$ at room temperature. After 10 days, the resulting culture was subjected to the same conditions of fragmentation described above and the turbidity of the resulting suspension was adjusted by comparison to McFarland's scale 5 $($ A625 = 0.8-1.0). This approach aimed at obtaining a

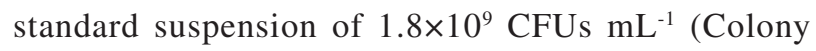
Forming Units), which would be used to inoculate the Petri dishes, using pour plate technique, ${ }^{11}$ and develop disk diffusion susceptibility assays according to CLSI M-44A guidelines (Clinical and Laboratory Standards Institute - Method for Antifungal Disk Diffusion Susceptibility Testing of Yeasts; Approved Guideline). All tests were performed in duplicate, using potato dextrose agar (PDA) and the following concentrations of each compound $1.2 \mu \mathrm{M} /$ disc and $0.6 \mu \mathrm{M} /$ disc. Positive-growth, negativegrowth and DMSO controls were employed in all assays. The process control was performed using Aspergillus niger ATCC 40036 and Tebuconazole at $0.6 \mu \mathrm{M}$, which provided a $30 \mathrm{~mm}$ diameter standard halo.

\section{Chemometrics analysis}

\section{Data set}

The data set used in QSAR studies consists of 33 azole derivatives whose chemical structures and the corresponding activity pattern are presented in Table 1 .

The chemical structures were drawn in the $2 \mathrm{D}$ format and converted to 3D, using SYBYL 8.1 (Tripos Inc., St. Louis, USA). All structures were single point optimized using the AM1 semi-empiric method (KEYWORDS: 1SCF XYZ ESP NOINTER NOMM SCALE $=1.4$ NSURF $=2$ $\mathrm{SCINCR}=0.4)$. A hierarchical cluster analysis, carried out with Pirouette 4.0 software (Infometrix, Washington, USA), using the complete linkage clustering method (Euclidean distances) and data autoscaling, guided the division of the complete dataset into training and test sets (marked with* in Table 1 and Figure 1) for external validation purposes. 


\section{Descriptor calculation and selection}

Calculation and selection of suitable descriptors required for chemometrics were carried out with DRAGON 5.5 (Talette SRL, Milan, Italy) and Pirouette 4.0 software (Infometrix Inc., Washington, USA). Briefly, 2D molecular descriptors, including topological descriptors, connectivity indices, 2D autocorrelation descriptors, Burden eigenvalues indices, among others, were computed using the DRAGON 5.5 software and used as independent variables in chemometric model development. A total of 854 molecular descriptors were calculated, but those with zero variance were discarded. Then, the Fisher weight was employed to select a subset of descriptors that are related to biological activity. The Fisher weight is a measure of the distance between two categories, ${ }^{12,13}$ which is calculated as follows:

$F=\frac{\left(\bar{x}_{p, 1}-\bar{x}_{p, 2}\right)^{2}}{S_{p, 1}+S_{p, 2}}$

Where $\bar{x}_{p, 1}, \bar{x}_{p, 2}$ denote the average values of descriptor $p$ in class 1 and class 2 respectively, and $S_{p, 1}, S_{p, 2}$ denote the standard deviation of descriptor $p$ in class 1 and class 2 , respectively.

2D descriptors which Fishers' weight value are above $95 \%$ of confidence interval (mean plus two times the standard deviation) (0.497) were selected, gathered, autoscaled and used in unsupervised exploratory analysis (HCA- Hierarchical Cluster Analysis and PCA- Principal Component Analysis) and supervised pattern recognition studies (SIMCA-Solft Independent of Class Analogy and KNN - K-Nearest Neighbors) available in the Pirouette 4.0 software (Infometrix Inc., Washington, USA) software.

\section{Chemometric model development and validation}

The internal consistency and robustness of KNN models and PCA was assessed by LOO (leave one-out) crossvalidation, which has also been applied to determine the number of principal components in PCA and neighbors in KNN. The real predictive power of chemometric models was evaluated by external validation protocol, which was performed with a test set of 9 compounds that were not considered during model development. The predictive ability of the models is expressed by the percentage of correctly classified compounds.

\section{Results and Discussion}

Identification of putative fungicides against $M$. perniciosa can be undertaken by comparing the diameter of growth or fungal mass formation of treated to untreated fungal colonies in solid or liquid cultures respectively., ${ }^{914}$ These methods are error prone though, as they depend on many factors such as irregular growth of filamentous fungi, survival of dry-fungus and so forth. Moreover, these strategies can hardly be adapted for high throughput screening. ${ }^{10}$ In order to circumvent this dilemma Filho and co-workers $(2006)^{10}$ developed quasi single-cell suspension from broken $M$. perniciosa hyphae, which can be used for susceptibility assays. Although NCCLS suggests that broth dilution tests should be employed for filamentous fungi (standard M-38A), agar-based methods such as E-test and disc diffusion are good alternatives to broth dilution testing, once they are simpler, faster and show good correlation with broth microdilution methods. ${ }^{15,16}$

Accordingly, it was possible to establish the antifungal susceptibility profile of 33 imidazole and triazole derivatives against $M$. perniciosa. Our biological assay shows that azole derivatives depicted in Figure 1 do not inhibit fungal growth under assayed conditions. On the other hand, metconazole and tebuconazole completely inhibited fungal growth under comparable conditions and the remaining 14 compounds partially inhibit fungal growth, as shown in Table 1.

Although diffusion disk protocols do not allow a quantitative evaluation of compounds potency, the biological assay clearly shows that not every azole derivative is effective against $M$. perniciosa in vitro (Figure 2). Moreover, as these azole derivatives have similar $\log \mathrm{P}$ values (ranging from 5.82 to 2.74 - MLOGP), and consequently similar diffusion rates in the PDA medium, it is reasonable to assume that their different inhibitory profile is a consequence of physicochemical and structural features that dictate their greater or smaller fungicidal activity towards $M$. perniciosa. Aiming at further investigate this subject unsupervised (HCA, PCA) and supervised (KNN, SIMCA) chemometric tools were employed.

Considering the high cost of fungicides available to WBD combat, it would be interesting to use the lowest concentration of fungicide that is effective against the causative fungus; therefore modeling was carried out with

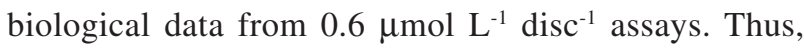
compounds with no inhibition halos under this condition (Figure 1) were considered "inactive" against M. perniciosa and the remaining compounds as "active" (Table 1).

The usefulness and predictive power of chemometric models is highly dependent on the chemical diversity of the dataset employed for its development. For this reason, the original dataset was split in training and test set (marked with * in Table 1 and Figure 1) according to the following criteria: $i$ ) a similar proportion of active and inactive compounds should be present in both datasets, since the 
<smiles>Clc1ccc(C2(Cn3cncn3)OCCO2)c(Cl)c1</smiles>

azaconazole<smiles>OC(Cn1cncn1)(Cn1cncn1)c1ccccc1F</smiles>

fluconazole<smiles>CCCCC(C)(Cn1cncn1)c1ccc(Cl)cc1</smiles>

myclobutanil*<smiles>c1ccc(-c2ccc(C(c3ccccc3)n3ccnc3)cc2)cc1</smiles>

bifonazole<smiles>CCCC1COC(Cn2cncn2)(c2ccc(Cl)cc2Cl)O1</smiles>

propiconazole<smiles>OC(Cn1cncn1)(c1ccc(F)cc1)c1ccccc1F</smiles>

flutriafol

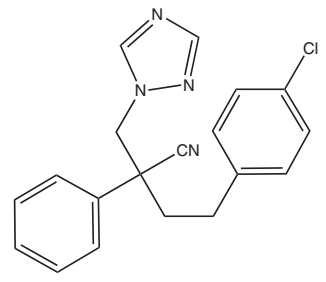

fenbuconazole

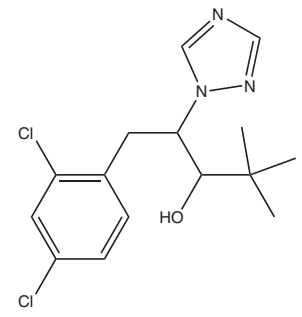

diclobutrazole<smiles>Clc1ccc(C2(Cn3cncn3)CC(Br)CO2)c(Cl)c1</smiles>

bromuconazole*<smiles>CS(Cn1cncn1)(c1ccc(F)cc1)c1ccc(F)cc1</smiles>

flusilazole<smiles>CCCC(Cn1cncn1)c1ccc(Cl)cc1Cl</smiles>

penconazole

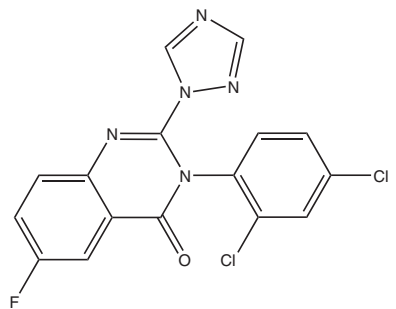

fluquinconazole<smiles>CCC1COC(Cn2cncn2)(c2ccc(Cl)cc2Cl)O1</smiles>

etaconazole*<smiles>C=CCOC(Cn1ccnc1)c1ccc(Cl)cc1Cl</smiles>

imazilil<smiles>FC(F)(F)c1cccc(C(Cn2cncn2)(c2ccccc2)c2ccccc2)c1</smiles>

fluotrimazole*

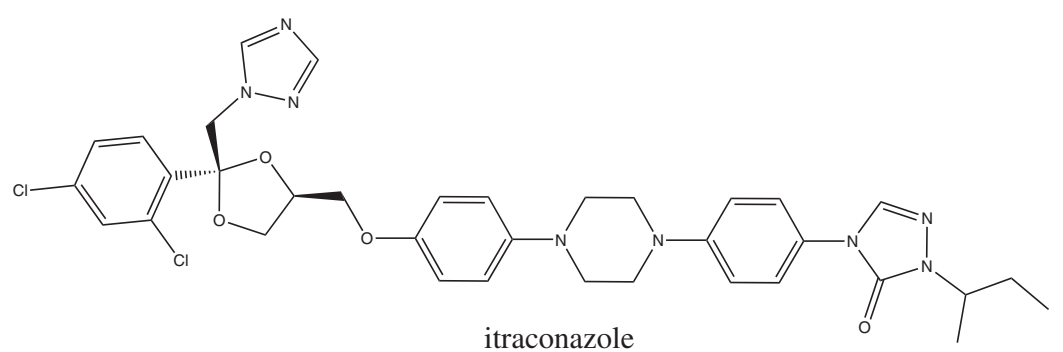

Figure 1. Azole derivates that are inactive against M. perniciosa when assayed at $0.6 \mu \mathrm{mol} \mathrm{L}^{-1} \mathrm{disc}^{-1}$ or $1.2 \mu \mathrm{mol} \mathrm{L}^{-1} \mathrm{disc}^{-1}$.

chemical space sampling of active and inactive compounds should be accounted for; $i i)$ the greater structural diversity in the training set the better. Thus, HCA was carried out, as described in experimental section, and compounds from each of the clusters, at $60 \%$ similarity, were randomly assigned to training and test set, as long as $44 \%$ of active compounds were kept in both datasets.

As no 3D structure of lanosterol $14 \alpha$-demethylase from M. perniciosa is available and considering that $2 \mathrm{D}$ descriptors have already proven useful to describe the biological activity 
Table 1. Inhibition halos $(\mathrm{mm})^{\mathrm{a}}$ of azol derivatives, according to disk diffusion assay, towards $M$. perniciosa $948 \mathrm{~F}$ strain. Test set marked with *

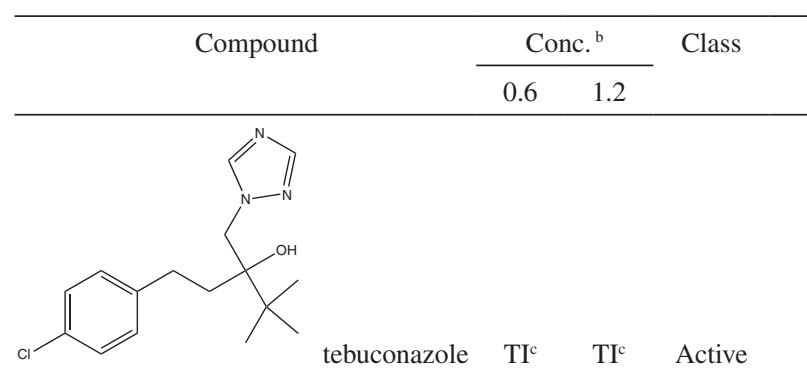
tebuconazole $\mathrm{TI}^{\mathrm{c}} \quad \mathrm{TI}^{\mathrm{c}} \quad$ Active

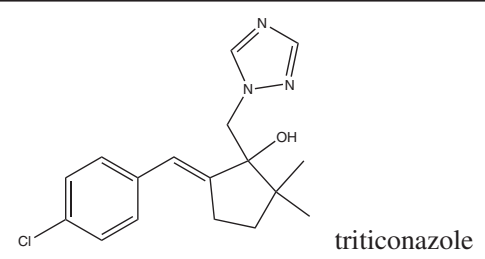

\begin{tabular}{ll} 
Conc. \\
\hline $0.6 \quad 1.2$
\end{tabular}

Class<smiles>CC1(C)CCC(Cc2ccc(Cl)cc2)C1(C)Cn1cncn1</smiles>

metconazole $\quad \mathrm{TI}^{\mathrm{c}} \quad \mathrm{TI}^{\mathrm{c}} \quad$ Active<smiles></smiles>

Active<smiles></smiles>

triadimenol

Active

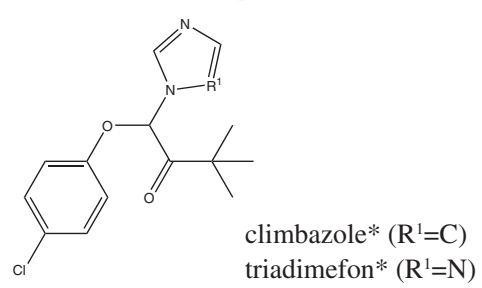

Active<smiles></smiles>
cyproconazole $\quad 30 \quad 38 \quad$ Active<smiles>Clc1ccc(C2CC3CCNCC3C2)c(Cl)c1</smiles>
triadimefon* $\left(\mathrm{R}^{1}=\mathrm{N}\right)$

Active Active<smiles>Clc1ccccc1C(c1ccccc1)(c1ccccc1)n1ccnc1</smiles>
clotrimazole

Active<smiles>CC1COC(Cn2ccnc2)(c2ccc(Cc3ccc(O)cc3)cc2Cl)O1</smiles><smiles></smiles>
diniconazole $\mathrm{NI}^{+}$

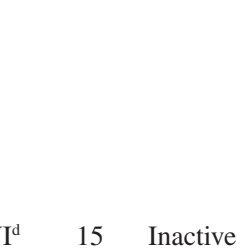<smiles></smiles>
econazole $\left(\mathrm{R}^{1}=\mathrm{O}, \mathrm{R}^{2}=\mathrm{H}\right)$
sulconazole* $\left(\mathrm{R}^{1}=\mathrm{S}, \mathrm{R}^{2}=\mathrm{H}\right)$
miconazole $\left(\mathrm{R}^{1}=\mathrm{O}, \mathrm{R}^{2}=\mathrm{Cl}\right)$ Active Active Active<smiles>CC(=O)N1CCN(c2ccc(OCC3COC(Cn4ccnc4)(c4ccc(Cl)cc4Cl)O3)cc2)CC1</smiles>
$\left(\mu \mathrm{mol} \mathrm{L}{ }^{-1}\right.$ disc $\left.^{-1}\right)$ employed in the biological assay; ${ }^{\mathrm{C}} \mathrm{TI}$ - Total inhibition; ${ }^{\mathrm{d}} \mathrm{NI}$ - no inhibition; *Test set compounds. 
(A)

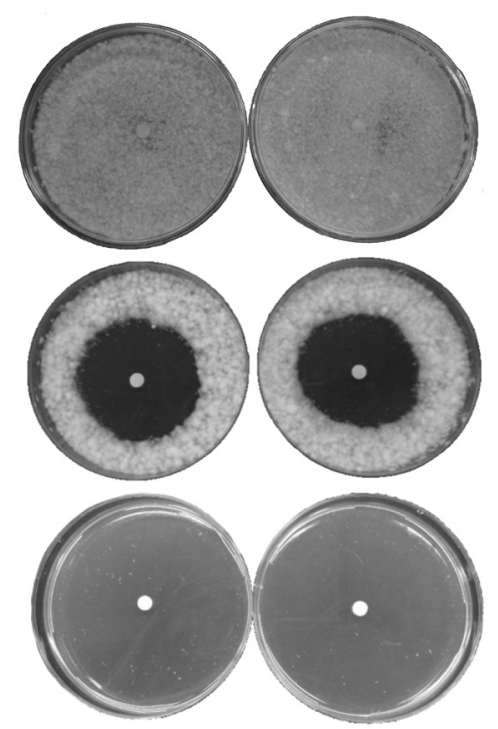

Figure 2. M. perniciosa growth inhibition in the presence of $0.6 \mu \mathrm{mol} \mathrm{L^{-1 }}$ fungicite ${ }^{-1}$ disc $^{-1}$ : (A) etaconazol, lack of inhibition; (B) econazole, halo of 40:38 mm; (C) tebuconazole, complete inhibition of growth.

of azole derivatives against Candida albicans, ${ }^{17}$ we resorted to a similar approach, instead of using 3D descriptors that are highly biased by molecular conformation. Thus, a total of $8542 \mathrm{D}$ descriptors were calculated in the DRAGON 5.5 software and used as independent variables in chemometric models development. A pre-selection protocol using Fishers' weight afforded the selection of 28 descriptors (Table 2) that were gathered, auto-scaled and used in unsupervised exploratory analysis and in supervised pattern recognition studies, as described below.

A Hierarchical Cluster Analysis shows that training set compounds can be grouped into two distinct classes at $40 \%$ similarity (Figure 3), though this division does not strictly

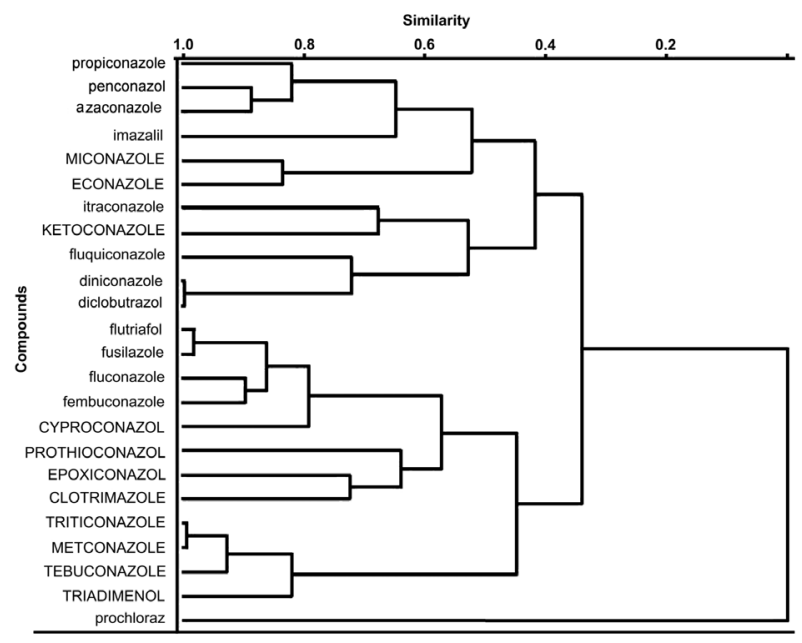

Figure 3. Hierarchical cluster analysis for the training set compounds. Active compounds are depicted in uppercase letters and inactive compounds in lowercase letters. follow the activity profile, approximately $70 \%$ of active compounds are clustered in a subfamily.

Table 2. Descriptors selected by the Fisher' weight. Descriptors in the SIMCA final model are marked in italic

\begin{tabular}{ll}
\hline Symbol & Description \\
MX & $\begin{array}{l}\text { Number of halogen atoms } \\
\text { Moran autocorrelation calculated between atoms } \\
\text { separated by } 4 \text { chemical bonds adjusted for the } \\
\text { atomic mass } \\
\text { Moran autocorrelation calculated between atoms } \\
\text { separated by 3 chemical bonds adjusted for the atomic } \\
\text { polarizabilities }\end{array}$ \\
BEHe3 & $\begin{array}{l}\text { Largest eigenvalue of the matrix of index 3 Burden, } \\
\text { adjusted for eletronegativity of atomic Sanderson }\end{array}$ \\
BELm8 & $\begin{array}{l}\text { Lowest of the matrix of index } 8 \text { Burden, adjusted by } \\
\text { atomic masses }\end{array}$ \\
JGI4 & $\begin{array}{l}\text { Topological charge index between atoms separated } \\
\text { by 4 chemical bonds } \\
\text { JGI10 }\end{array}$ \\
Topological charge index between atoms separated \\
by 10 chemical bonds \\
C-001
\end{tabular}

B04[Cl-Cl] Presencelabsence of Cl-Cl fragment at 04 topological distance

B05[N-Cl] Presence/absence of $\mathrm{N}-\mathrm{Cl}$ fragment at 05 topological distance

B06[C-O] Presencelabsence of C-O fragment at 06 topological distance

B06[N-Cl] Presencelabsence of N-Clfragment at 06 topological distance

B07[C-O] Presencelabsence of C-O fragment at 07 topological distance

B08[N-Cl] Presence/absence of $\mathrm{N}-\mathrm{Cl}$ fragment at 08 topological distance

B09[C-C] Presence/absence of C-C fragment at 09 topological distance

B09[C-N] Presence/absence of C-N fragment at 09 topological distance

B10[C-C $]$ Presence/absence of C-C fragment at 10 topological distance

B10[C-N] Presence/absence of C-N fragment at 10 topological distance

B10[C-Cl] Presence/absence of C-Cl fragment at 10 topological distance

F04[Cl-Cl] Frequency of $\mathrm{Cl}$ - $\mathrm{Cl}$ fragment at 04 topological distance

$\mathrm{F04}[\mathrm{C}-\mathrm{Cl}] \quad$ Frequency of $\mathrm{C}$-Cl fragment at 04 topological distance $\mathrm{F} 05[\mathrm{~N}-\mathrm{Cl}] \quad$ Frequency of $\mathrm{N}-\mathrm{Cl}$ fragment at 05 topological distance

F06[N-Cl] Frequency of N-Cl fragment at 06 topological distance

$\mathrm{F} 07[\mathrm{~N}-\mathrm{Cl}] \quad$ Frequency of N-Cl fragment at 07 topological distance

F08[C-N] Frequency of C-Nfragment at 08 topological distance

F08[N-Cl] Frequency of N-Cl fragment at 08 topological distance 
Somewhat more encouraging results were available from Principal Components Analysis (PCA), which affords a data dimensionality reduction without significant loss of chemical information. In fact the first 3 PCs account for $80.6 \%$ of data variance. Furthermore, the visual analysis of score plot, that reveals compounds positioning according to PC1 vs. PC2 space coordinates, shows that active compounds are grouped between values -2.1 and 1 in $\mathrm{PC} 1$, whilst the majority of inactive compounds $(92.3 \%)$ are outside of this range (Figure 4). This data suggests that the first principal component can be used to distinguish active from inactive compounds.

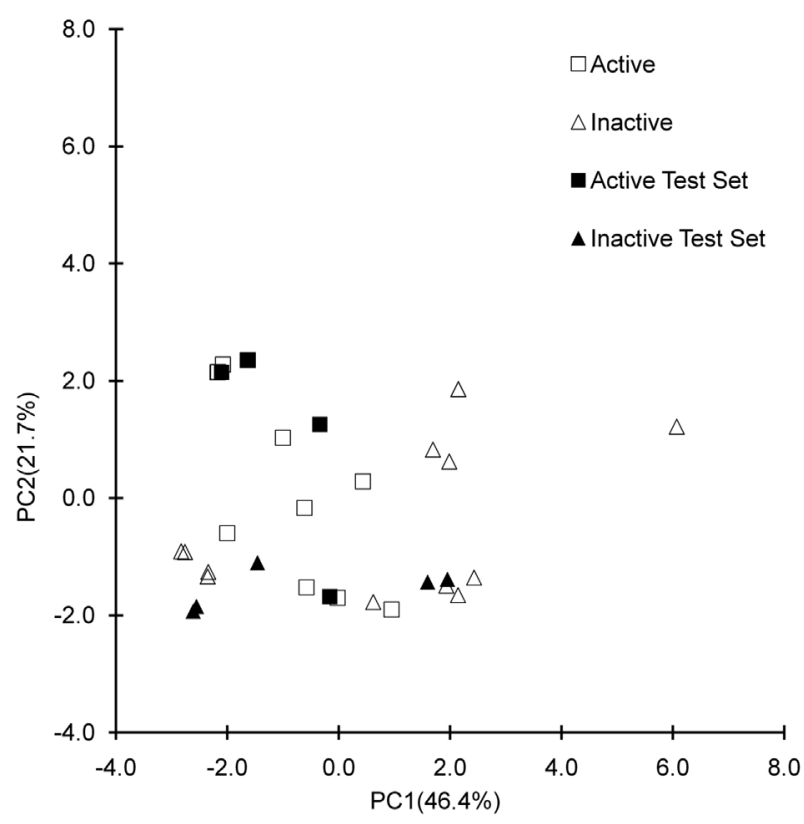

Figure 4. Score plot of principle component analysis.

In order to investigate this hypothesis, the relevance of each descriptor to the overall result was analyzed. As shown in Figure 5, MATS4m, BEHe3, F04[Cl-Cl], F04[C$\mathrm{Cl}]$ and $\mathrm{B} 04[\mathrm{Cl}-\mathrm{Cl}]$ are the most important descriptors to $\mathrm{PC} 1$, and thus to fungicidal activity. Taking BEHe3 as an example, its negative value in PC1 suggests that azole's electronegativity profile plays an important role in $M$. perniciosa growth inhibition. Likewise, the frequency (F04[Cl-Cl] and F04[C-Cl]) and the count (B04 [Cl-Cl]) of fragments that have electron negative atoms at a topological distance of four bonds display major positive contributions to $\mathrm{PC} 1$ also underscores the role of electrostatic interactions for azoles' activity. Other critical feature that seems relevant is the steric fit of compounds towards their biological target, as MATS4m accounts for the molecular weight of azoles and thus, indirectly, to the volume they occupy in their binding site. In order to evaluate the predictive power of PCA, it was used to predict the activity of the test set compounds: $88 \%$ of test set compounds were correctly classified, whereas myclobutanil is misclassified.

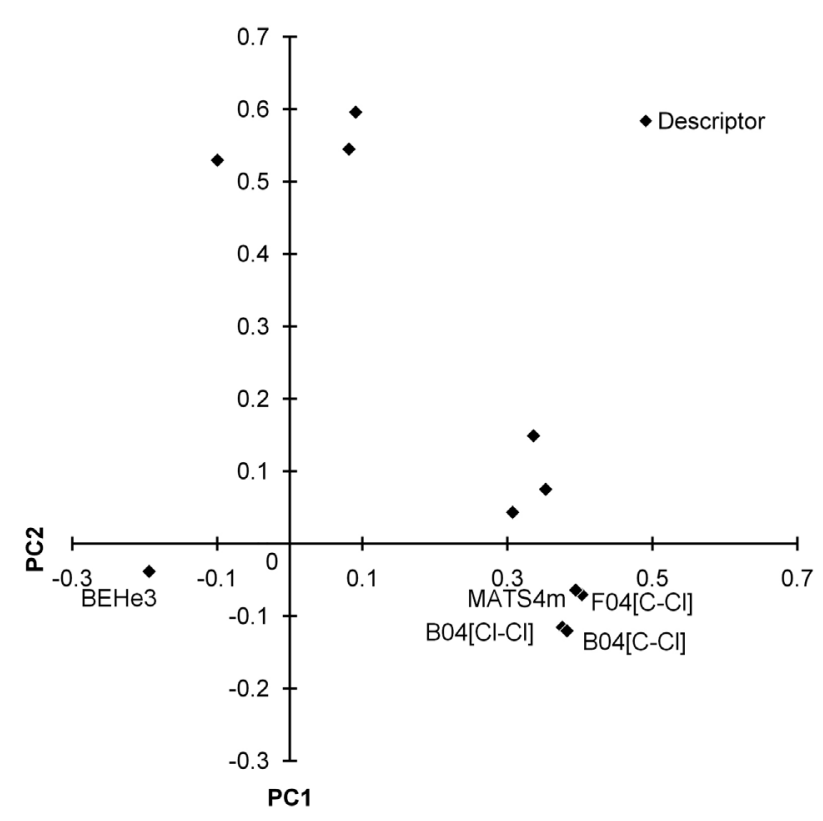

Figure 5. Loading plot of principle component analysis.

Aiming at further improving the predictive power of our models, the inhibitory profile was employed to build supervised pattern recognition models by means of KNN and SIMCA. KNN shows good internal consistency and high predictive power as $91 \%$ of active and $100 \%$ of inactive training set compounds and $100 \%$ of test set compounds are correctly classified. However, this chemometric tool provides modest information on the chemical and structural properties that are responsible for the azole derivatives fungicidal activity against $M$. perniciosa.${ }^{18}$ On the other hand, SIMCA not only offers information on the influence of each descriptor to the separation and modeling of classes ${ }^{19}$ but also allows for a better accounting of chemical dissimilarity, as compounds can be classified into more than one class or even none. ${ }^{20}$ In addition, the best SIMCA model correctly classifies $100 \%$ of test set compounds, using 3 PC's for each class (Figure 6). The final SIMCA model employs only 12 from the original 28 descriptors that were iteratively selected for their discriminating power and modeling power contribution to the model.

As pointed out previously, useful chemometric models should emphasize chemical information that might guide the identification and optimization of novel fungicides against $M$. perniciosa. In order to gain some insight into this subject, the most important descriptor for discriminating power were analyzed. As shown in Figure $7 \mathrm{~F} 08[\mathrm{~N}-\mathrm{Cl}]$, and F06[N-Cl], and BEHe3 are the most important descriptors for discriminating active from inactive compounds. 


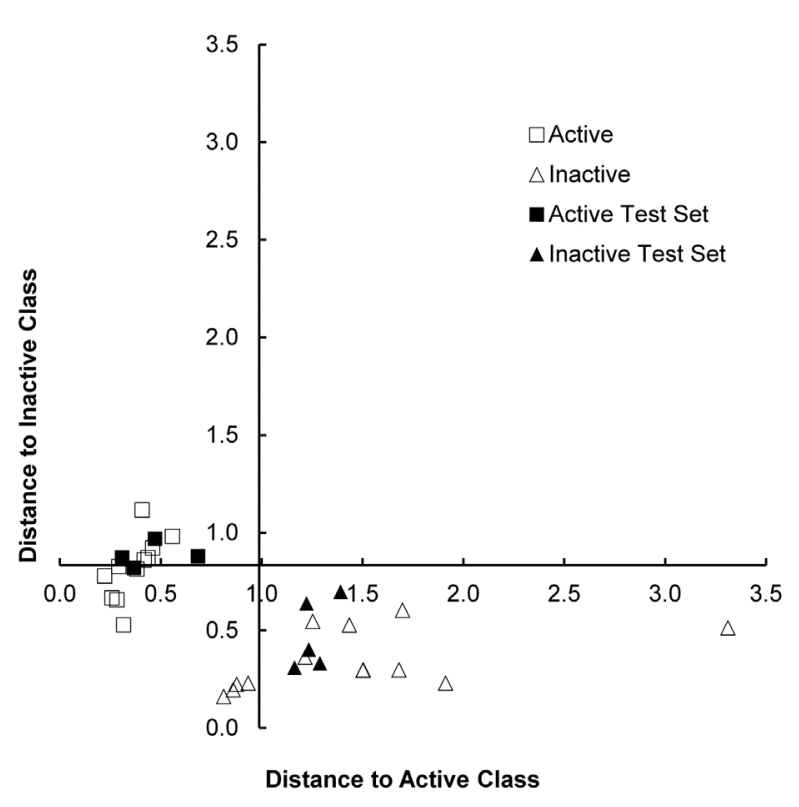

Figure 6. Interclass distance of training and test set active and inactive compounds according to SIMCA (Interclass Distance 2.38).

$\mathrm{F} 08[\mathrm{~N}-\mathrm{Cl}]$ and $\mathrm{F} 06[\mathrm{~N}-\mathrm{Cl}]$ are sub-structural descriptors that express the frequency of $\mathrm{N}-\mathrm{Cl}$ fragment at a 08 or 06 topological distance, respectively. Whereas the presence of one of these fragments is tolerated in active compounds, $50 \%$ of inactive compounds have both simultaneously. $\mathrm{BEHe} 3$ is a Burden eigenvalue descriptor based on a combination of the atomic number for each atom and a nominal description of the type of connection between adjacent and non adjacent atoms. This sort of descriptor can incorporate connectivity information and atomic properties (e.g., atomic charge, polarizability, H-bonding) that are relevant to intermolecular interactions. ${ }^{21} \mathrm{BEHe} 3$, in particular, accounts for the electronegativity of atoms that are separated by 3 bonds. ${ }^{22}$ In general active compounds have $\mathrm{BEHe} 3$ values between 3.6 to 3.8 , whereas inactive compounds have broader range of values. This result is in good agreement with PCA results.

As independent PCAs are carried out for each class of compounds, it is possible to further investigate the descriptors contribution to each $\mathrm{PC}$, as well as visualize active compounds in PC1XPC2 low dimension coordinate space. In fact this analysis reveals that the most active compounds are clustered in the lower left quadrant of score plot (Figure 8).

Thus, descriptors with great influence on PC1 (JGI4) and PC2 (B06 [CO] and B07 [CO]) (Figure 9) are somehow important to azole's fungicidal activity against M. perniciosa.

$\mathrm{B} 06[\mathrm{CO}]$ and $\mathrm{B} 07[\mathrm{CO}]$ are sub-structural descriptors that describe the presence of the $\mathrm{C}$-O topological fragment in 06 or 07 distance, respectively. ${ }^{21}$ It is reasonable to

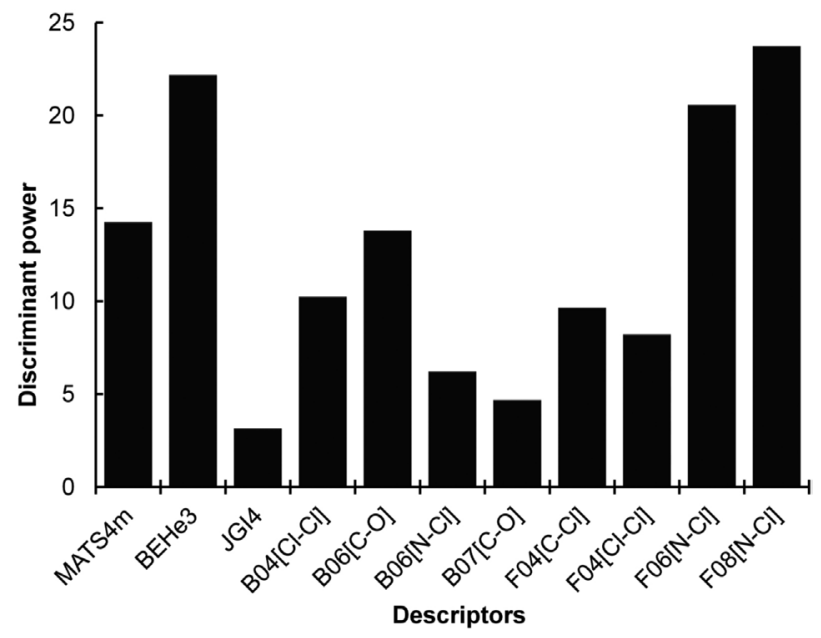

Figure 7. Discriminating power of the descriptors selected according to SIMCA.

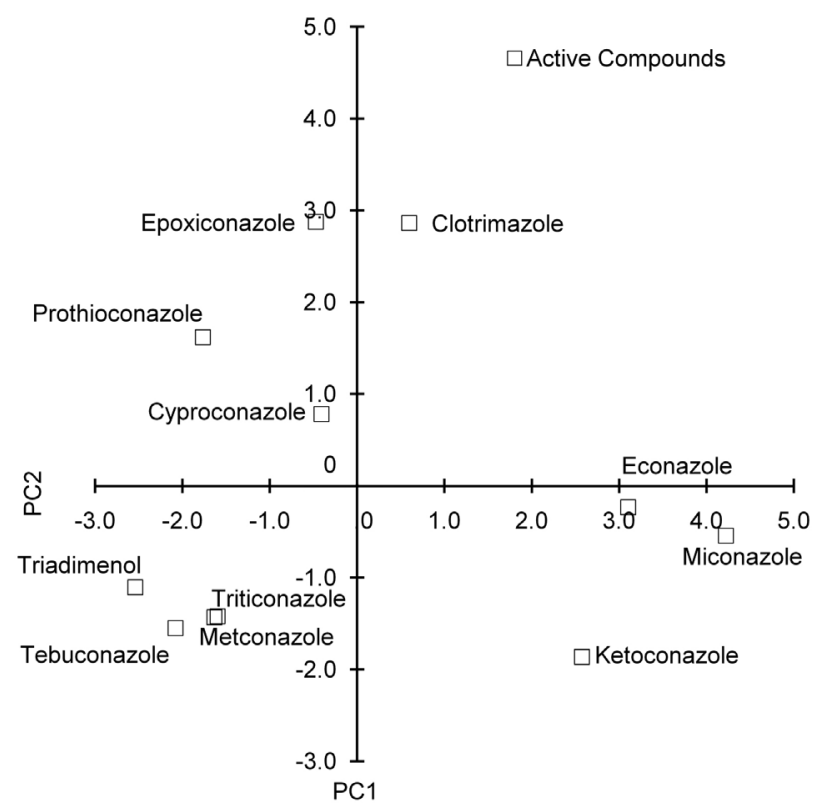

Figure 8. Principal components analysis for training set active compounds against $M$. perniciosa according to SIMCA.

assume that this fragment describes the H-bonding capability of active compounds. JGI4 is a topological descriptor, known as charge index, which measures the charge transfer between pairs of atoms separated by four bonds, and consequently, the global transfer of charge in the molecule (e.g., the dipole moment). ${ }^{23}$ The most active compounds (triadimenol, triticonazole, tebuconazole and metconazole) have both fragments and high dipole moment. In fact the importance of charge transfer between azole derivatives and the iron atom of lanosterol $14 \alpha$-desmethylase active site heme portion has already been reported. ${ }^{24-27}$ Taken together, this analysis suggests that the dipole moment (JGI4) and the presence of the C-O fragment at topological distance of 06 and 07 , that relates 
to $\mathrm{OH}$ in the most active compounds, are important for the largest activity of these compounds.

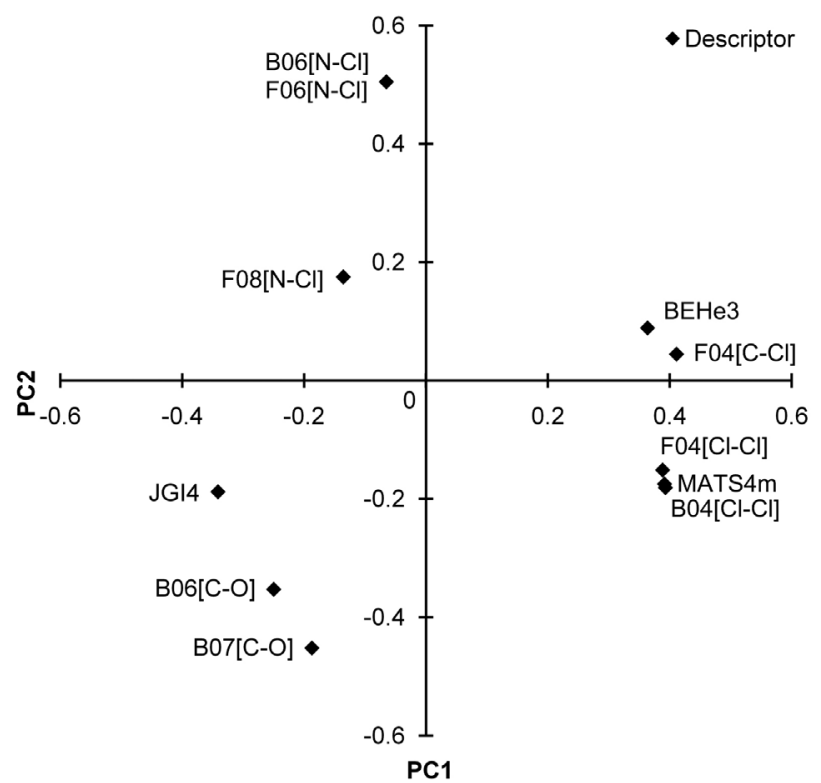

Figure 9. Selected descriptors importance for the PC1 and PC2 according to SIMCA model.

\section{Conclusions}

A comprehensive description of chemical and structural features that are required for M. perniciosa growth inhibition is still limited by the great variability and lack of minimum inhibitory concentration (MIC) standard assays for filamentous fungi. Therefore, at this point only qualitative insights are available. Accordingly, chemometric analysis suggests that azoles with improved inhibitory activity against $M$. perniciosa should not only interact with the heme, but also hydrogen bond to lanosterol $14 \alpha$-desmethylase active site. Furthermore, $\mathrm{Cl}$ atoms 6 to 8 bonds from the azole's nitrogen atoms should be avoided if potent antifungal activity is to be expected.

\section{Acknowledgments}

We gratefully acknowledge financial support from the State of Bahia Research Foundation (FAPESB) and the Research and Projects Financing Foundation (FINEP), Brazil-3696/06.

\section{References}

1. Kilaru, A.; Bailey, B. A.; Hasenstein, K. H.; FEMS Microbiol. Lett. 2007, 274, 238.

2. Rincones, J.; Scarpari, L. M.; Carazzolle, M. F.; Mondego, J. M.; Formighieri, E. F.; Barau, J. G.; Costa, G. G.; Carraro, D.
M.; Brentani, H. P.; Villa-boas, L. A.; de Oliveira, B. V.; Sabha, M.; Dias, R.; Cascardo, J. M.; Azevedo, R. A.; Meinhardt, L. W.; Pereira, G. A. G.; Mol. Plant-Microbe Interact. 2008, 2 , 891.

3. Garcia, O.; Macedo, J. A.; Tibúrcio, R.; Zaparoli, G.; Rincones, J.; Bittencourt, L. M.; Ceira, G. O.; Micheli, F.; Gesteira, A.; Mariano, A. C.; Schivianato, M. A.; Medrano, F. J.; Meinhardt, L. W.; Pereira, G. A.; Cascardo, J. C.; Mycol. Res. 2007, 111, 443.

4. Pereira, J. L.; de Almeida, L. C. C.; Santos, S. M.; Crop Prot. 1996, 15, 743.

5. Purdy, L. H.; Schmidt, R. A.; Annu. Rev. Phytopathol. 1996, 34, 573.

6. Oliveira, M. L.; Luz, E. D. M. N.; Identificação e Manejo das Principais Doenças do Cacaueiro no Brasil, CEPLAC/CEPEC/ SEFIT: Ilhéus, Brasil, 2005, p. 132.

7. Rincones, J.; Mazotti, G. D.; Griffith, G. W.; Pomela, A.; Figueira, A.; Leal, G. A.; Queiroz, M. V.; Pereira, J. F.; Azevedo, R. A.; Pereira, G. A.; Meinhardt, L. W.; Mycol. Res. 2006, 110, 821.

8. Silva, J. R. Q.; Figueira, A.; Pereira, G. A. ; Albuquerque, P.; Mol. Ecol. Resour. 2008, 8, 783.

9. McQuilken, M. P.; Supriadi; Rudgard, S. A.; Plan. Pathol. 1988, $37,499$.

10. Filho, D. F.; Pungartnik, C.; Cascardo, J. C. M.; Brendel, M.; Curr. Microb. 2006, 52, 407.

11. Lima, E. O.; Gompertz, O. F.; Giesbrecht, A. M.; Paulo, M. Q.; Mycoses 1993, 36, 333.

12. Cavalcanti, A. R. O.; Leite, E. S.; Neto, B. B.; Ferreira, R.; Orig. Life Evol. Biosph. 2004, 34, 407.

13. Wang, K. L.; Wen, Z. N.; Nie, F. S.; Li, M. L.; Chin. Chem. Lett. 2005, 16, 1133.

14. Raynor, L.; Mitchell, A.; Walker, R.; Walker, K.; Mycopathologia 2004, 157, 87.

15. López-Oviedo, E.; Aller, A. I.; Martin, C.; Castro, C.; Ramirez, M.; Pemán, J. M.; Cantón, E.; Almeida, A.; Martín-Mazuelos, E.; Antimicrob. Agents Chemother. 2006, 50, 1108.

16. Serrano, M. C.; Ramiréz, M.; Morilla, D.; Valverde, A.; Chavéz, M.; Espinel-Ingroff, A.; Claro, R.; Fernandéz, A.; Almeida, C.; Martín-Mazuelos, E.; J. Antimicrob. Chemother. 2004, 53, 739.

17. Mota, S. G. R.; Barros, T. F.; Castilho, M. S.; J. Braz. Chem. Soc. 2009, 20, 451.

18. Gonzáles-Arjona, D.; Gonzáles, A. G.; Anal. Chim. Acta 1998, $363,89$.

19. Moita Neto, J. M.; Moita, G. C.; Quim. Nova 1998, $21,467$.

20. Branden, K. V.; Hubert, M.; Chemom. Intell. Lab. Syst. 2005, $79,10$.

21. González, M. P.; Teran C.; Teijeira, M.; Besada, P.; GonzalezMoa, M. J.; Bioorg. Med. Chem. Lett. 2005, 15, 3491.

22. Burden, F. R.; Quant. Struct.-Act. Relat. 1997, 16, 309. 
23. Gálvez, J.; García-Domenech, R.; Salabert, M. T.; Soler, R.; J. Chem. Inf. Comput. Sci. 1994, 34, 520.

24. Ji, H.; Zhang, W.; Zhang, M.; Kudo, M.; Aoyama, Y.; Yoshida, Y.; Sheng, C.; Song, Y.; Yang, S.; Zhou, Y.; Lu, J.; Zhu, J.; J. Med. Chem. 2003, 46, 474.

25. Sheng, C.; Zhang, W.; Ji, H.; Zhang, M.; Song, Y.; Xu, H.; Zhu, J.; Miao, Z.; Jiang, Q.; Yao, J.; Zhou, Y.; Zhu, J.; Lu, J.; J. Med. Chem. 2006, 49, 2512.
26. Tafi, A.; Anastossopoulou, J.; Theophanides, T.; Botta, M.; Corelli, F.; Massa, S.; Artico, M; Costi R.; Di Santo, R.; Ragno, R.; J. Med. Chem. 1996, 39, 1227.

27. Tafi, A.; Costi, R.; Botta, M.; Di Santo, R.; Corelli, F.; Massa, S.; Ciacci, A.; Manetti, F.; Artico, M.; J. Med. Chem. 2002, 45, 2720 .

Received: June 29, 2009 Web Release Date: December 11, 2009 